\title{
An Efficient Utilization of Robotics and IoT to Overcome Threats of Pesticides
}

\author{
Araso Taye Waktola , J. Saravanan , B. Annapurna, Raushan Kumar Singh
}

\begin{abstract}
Agriculture is the most important occupation all over the world. At the global level, the crops produced get damaged by pests and pathogens by 10 to 40 per cent. If the proper pesticides are not used this data can reach up to $70-90 \%$ which can cause severe food crisis and all economy might crash. To overcome the situation the immediate solution is the pesticides. Pesticides were used to reduce the damage of crops to much extent. The use of pesticides now created a new problem i.e. cancer in farmers. Pesticides are nothing but a combination of hundreds of synthetic and natural chemicals. All over the world mainly three chemicals are used as pesticides lindane, arsenic and ethylene oxide. These are the topmost chemicals categorized as carcinogens as stated by the International Agency for Research on Cancer (IARC). Whenever farmers use the pesticides in any form irrespective of what they use as precaution majors some amount of pesticides comes in contact with the farmer. The protective gears like masks, gloves, shoes and glasses can protect the pesticides coming in contact with the human but $100 \%$ stoppage is impossible to second problems is the farmers mostly avoid the usage of protective gears due to its cost and the uneasy feeling to wear it during the work. We plan to create a hybrid system. If IoT and Robotics to overcome the above-stated problem our robot is equipped with the sprayer and mobile phone controlled navigation system. It can show its locations on Google map as well. Farmers can operate the robot from a safer distance. They can spray the pesticides and at the same time upload all the data logs of the IoT cloud server. The time of robots started how many time and for how much time the pesticides were sprayed can be monitored from any remote location throughout the world. This solves the problem of farmers coming in contact with pesticides as well as online monitoring of work done efficiently. The robotics system operates over Atmega 328p Pu microcontroller and IoT system over ESP8266 module of Wi-Fi-based internet system.
\end{abstract}

Index Terms: Carcinogens Lindane, Arsenic, Ethylene Oxide, IARC

\section{INTRODUCTION}

Agriculture is the most important occupation which feeds in terms of capital, defense or technology is considered secondary in comparison to food production. A country which can feed the mouth of their countrymen is termed to be an Ideal Nation. Farming is a topic which is crucial enough but is considered really minutely. India is an agriculturally advanced country from centuries. To protect the crops from pests and weed, pesticides are used from a very long time. The

Revised Manuscript Received on December 30, 2019.

Mr. Araso Taye Waktola, Head of Electrical and Computer Engineering department at Bule Hora University, Ethiopia

Mr. J. Saravanan, lecturer in Bule Hora University, Ethiopia

Dr. B. Annapurna, Assoc. Prof. in Computer Science and Engineerig Aditya College of Engineering, Surampalem , East Godavari Dt., AP, India.

Mr. Raushan Kumar Singh, Technical Director, Spectrum Solutions, Pondicherry, India the stomach of all country people. A country is strong enough

pesticides used before were mainly made up of herbal products like neem, aloe vera, cow dungs but today's available pesticides are developed using very harmful chemicals. These chemicals need to be sprayed on the plants directly instead of providing in soil.

These pesticides used are mostly given with protective gears like gloves, glass and mask but mostly it remains unused. It is mainly due to negligence, high price, poverty and illiteracy. Though, if we use protective gears and spray pesticide. A marginal amount of pesticide enters our body by means of air, water or skin. This is very harmful and can cause the problems from as minor as skin rashes to as major as cancer of lungs, stomach or skin. To overcome the problem several kinds of research have been done but all the remedial actions were not as feasible which can be implemented.

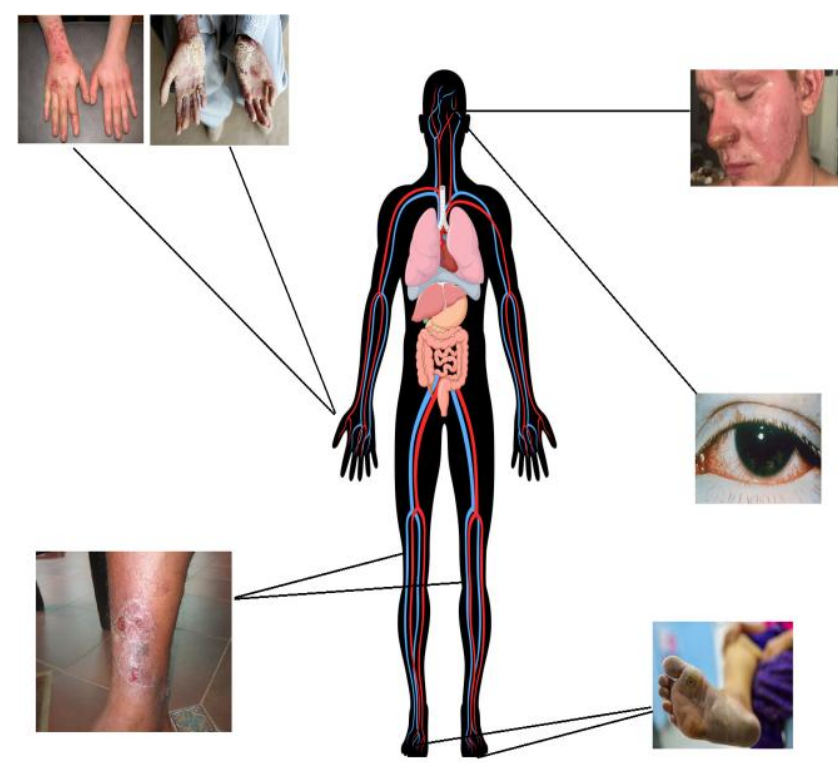

Fig. 1.1 - Pesticide Reaction on Different Body Parts

We deal hear with robotics sprayers where we used robots to spray the pesticides on plants and farmer remains untouched against the ill effects of pesticides. Our robotic system can be operated from a safer distance and can also spray the pesticides very easily.

It is fitted on a wirelessly controlled robot which makes it getting operated from a safer distance. We use a motor connected to the sprayer tank and a powerful motor which can spray pesticides over a long distance. If the system is implemented, farmers who fear to use pesticides will start using it without getting any damage and tones of crop getting wasted will be used to feed the deserving population. 
We also consider the components used should not be costly enough.

These are many possibilities to do changes as per the field, type of pesticides and crop. Next section is for a survey of literature which shows us the research we have done to create the solution of the problem and develop the paper.

\section{LITERATURE SURVEY}

[1]. Tosaki K, Miyahara S, Ichikawa T, Taniai S etc. explained in their paper that drones can be used to spray the pesticides in the field. They can use it in the orchard field to reduce the noise produced during the pesticides spray machine and pesticides coming in contact with the human body. Airblast sprayer system will be used to perform the tasks. The system was planned to decide the fruit plantation. If it is used for crops like rice, wheat and other cereals it will be a huge wastage of pesticide due to its loss in air. It will fly away from the field due to air produced by drone fins. Another issue is the cost and maintenance of such drones. The drones which can lift heavy weights and fly for longer durations will be much costlier farmers also need technical pieces of training to operate those drones otherwise it may crash anytime. Considering all those ideas we concluded that this system might be efficient for a costly crop like an orchid but cannot be feasible for Indian standards of farming. We need here much cheaper but efficient alternatives.

[2]. Van Henten E.J, Hemming J., Van Tuiil etc. explained in their paper about cucumber picking robot which can help farmers to pluck the cucumber with lesser time and with the great case. The proposed ' $A$ *' algorithm in which they planned collision-free motion planning with fast and accurate eye-hand coordination mechanism. This system was planned for a much smarter robot which can pluck the cucumbers for the farmer. For our proposed project we got the idea about creating a robot which can take the pesticide filled the tank and spray over the plants. The system gave us an idea about the creation of the robot and its utilization in the agricultural field.

[3]. Michelini R. C., Razzoli R. P, Acaccia G. M, Molfino $\boldsymbol{R}$. $\boldsymbol{M}$ explained in their paper about a robotic system which could efficiently handle the works like checking the health conditions of the plant, provide adequate pesticide and pluck the fruits. They proposed a robotic system to do tasks based on different mechanical logics. They also engineered the robotic hand using Pro/Engineer CAD modeler. This could enable them with better static stability and operation of robotic systems. The robotic hand used in the project was also enabled with the cutter to pluck the fruits from the plant. The strength merged with the delicacy of robotic handling gave immediate stability to the system. More than implementation paper it was a research and survey approach in which they went through several issues and analysis in the concerned domain. The outcome considered was one of the consideration points for our proposed paper and robotic system design.

Next section deals with the existing approach taken to create our proposed system. We went through the drawbacks and issues in already available system to come to a system which is much efficient and reliable to use.

\section{AN EXISTING APPROACH}

\section{Track based robotic system of pesticide spray}

During our research to make the paper and robotic system we went through several existing approaches but the system available here was most near to our idea. We went through a paper about a robotic system which can move with pesticides over the steel pipe. The steel pipe holds the robot while moving the robot sprayer keeps working and sprays chemicals over the plant. This makes the system very efficient as we don't need human intervention to spray the pesticide over the plant. It can help the framers to spray the pesticide of any form. The Robotics system moves on a nylon wheel assembly to intact movement. It has many advantages like the system can carry a large amount of pesticide but irrespective of advantages it has some drawbacks. [3]

\subsection{Drawbacks}

1. The robot can move only on the track that too in forward or reverse

2. We need to make tracks over the field across the plants to make this system working

3 . There is no monitoring unit.

4. It is not possible to maintain a database of when the robot started and when it stopped using when spray was on etc.

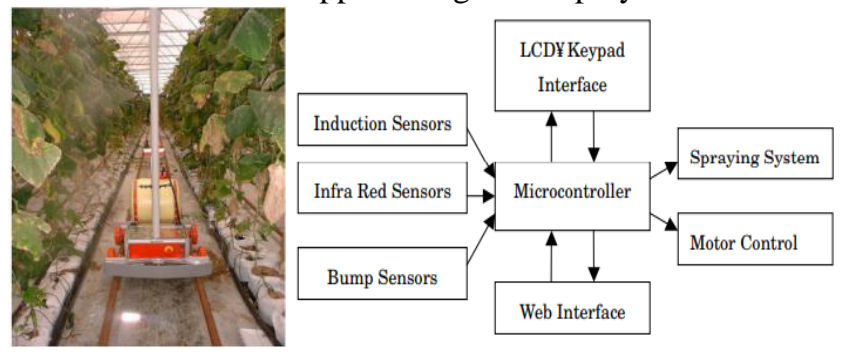

Fig. 3.1:- An Existing Approach

Our project is the advancement of the existing system by adding some advanced feature like IoT based data maintenance system for online cloud upload, wireless controlled robotic system, wireless controlled robot.

Next section of the paper deals with the implementation and discussion over the topic to make this paper.

\section{PROPOSED IMPLEMENTATION AND DISCUSSION \& RESULTS}

The proposed system deals with the wirelessly controllable robot. It can spray the pesticide on the plants whenever the wireless command is provided by the users. It also provides the facility of IoT updates which enables the robot to update its start, spray and spray off conditions. It has Bluetooth wireless controlled system to provide wireless connectivity. We have also used the pesticide sprayer motor to point the spray on the plant from a longer distance. 


\subsection{Implementation System}

The proposed concept is equipped with Bluetooth based wireless controlled device to control the robot from longer distance. It also has the IoT feature to update the information on Cloud Server. We use the bigger wheels to move the robot through tough terrain.

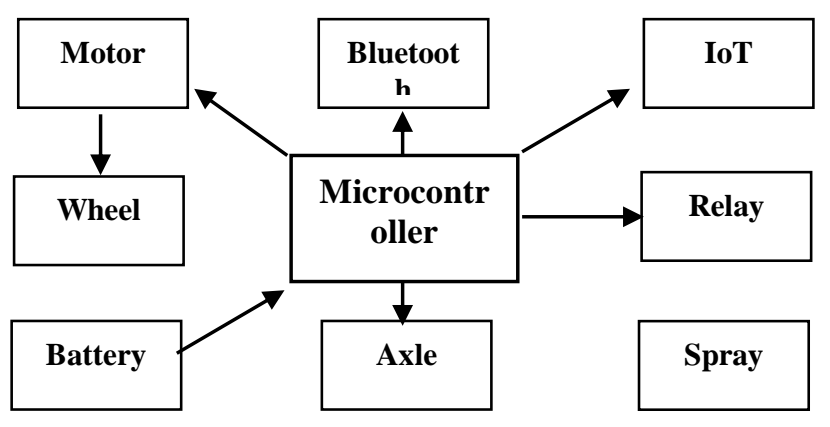

Fig. 4.1 - Proposed Block Diagram

\subsection{Microcontroller Program}

\section{\#include <SoftwareSerial.h> //Serial Communication at}

\section{IDE Library}

// include the library code:

// initialize the library with the numbers of the interface pins SoftwareSerial mySerial $(0,1)$;

$$
\begin{aligned}
& \text { int channel1 }=9 ; \\
& \text { int channel2 }=8 ; \\
& \text { int channel3 }=7 ; \\
& \text { int channel4 }=6 ; \\
& \text { int channel5 }=5 ;
\end{aligned}
$$

\section{\#define MOTOR 13}

void $\operatorname{setup}()$

\{

mySerial.begin(9600);

Serial.begin(9600);

Serial.println("*");

Serial.println("--AGRICULTURE ROBOT

\section{ACTIVATES--");}

delay(1000);

Serial.println("\#");

delay(1000);

pinMode(channel1, OUTPUT);

pinMode(channel2, OUTPUT);

pinMode(channel3, OUTPUT);

pinMode(channel4, OUTPUT);

pinMode(channel5, OUTPUT);
digitalWrite(channel1,LOW);

$\operatorname{delay}(50)$;

digitalWrite(channel4,LOW);

delay(50);

digitalWrite(channel2,LOW);

delay (50);

digitalWrite(channel3,LOW);

\}

void loop()

\{

char Char_string $=$ mySerial.read () ;

if $\left(\right.$ Char_string $==$ ' $^{\prime}$

\{

digitalWrite(channel2,LOW);

delay(50);

digitalWrite(channel3,LOW);

$\operatorname{delay}(50)$;

digitalWrite(channel1,HIGH);

delay(50);

digitalWrite(channel4,HIGH);

\}

if $($ Char_string $==$ 'B')

\{

digitalWrite(channel1,LOW);

$\operatorname{delay}(50)$;

digitalWrite(channel4,LOW);

$\operatorname{delay}(50)$;

digitalWrite(channel2,HIGH);

$\operatorname{delay}(50)$;

digitalWrite(channel3,HIGH);

\}

if $($ Char_string $==$ 'C')

\{

digitalWrite(channel2,LOW);

$\operatorname{delay}(50)$;

digitalWrite(channel4,LOW);

$\operatorname{delay}(50)$;

digitalWrite(channel1,HIGH);

delay(50); 
digitalWrite(channel3,HIGH);

\}

if $($ Char_string == 'D')

\{

digitalWrite(channel1,LOW);

delay(50);

digitalWrite(channel3,LOW);

delay(50);

digitalWrite(channel2,HIGH);

delay(50);

digitalWrite(channel4,HIGH);

\}

\subsection{Pesticide Robot Frame Implementation}

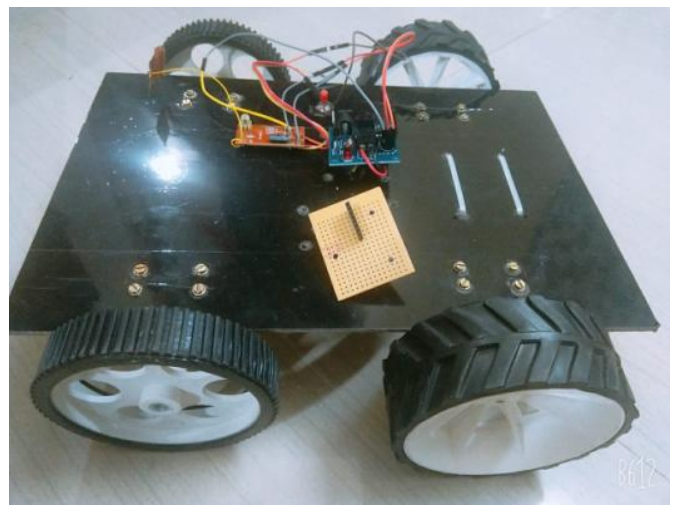

Fig. 4.2 - Pesticide Robot Top View

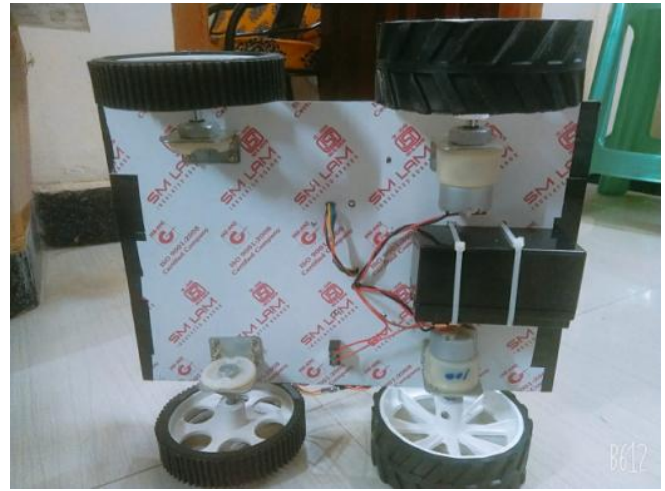

Fig. 4.3 - Pesticide Robot Bottom View

\section{CONCLUSION AND FUTURE ENHANCEMENT}

Thus we developed a robot of pesticide spray system which enables us to help the farmers against the different types of disease they get due to pesticides. The components used here are of lower cost so that farmers can afford them. We have also used the lower cost connectivity device which can be readily replaced with long distance wireless controllers. The system can be implemented directly by just increasing the size of wheel and robotic chassis. If we use the tracked wheel in future with the robot it can be converted into all-terrain vehicle and can move almost in any part of the terrain.

\section{REFERENCE}

1. Bovey R. "La défence des plantes cultivées. Editions Payot Lausanne", 1967.

2. L. Pasinetti. "Malattie delle piante", Hoepli, Milano, 1952.

3. Mandow, J. M. Gómez-de-Gabriel, J. L. Martínez, V. F. Muñoz, A. Ollero and A. García-Cerezo "The Autonomous Mobile Robot AURORA for Greenhouse Operation" Robotics and Automation Vol. 3, N4, pp. 18-28, December 1996.

4. Buemi F., Magrassi M., Mannucci A., Massa M., Sandini G. "The vision system for the agrobot project", Proc. 5th ASAE International Conference on Computers in Agriculture, Orlando, 1994.

5. Sezen, B. (2003), "Modelling Automated Guided Ve-hicle Systems in material Handling”, Dogus Univer-sitesi Dergisi, Vol 4, No. 3, pp. 207-216

6. Hopkins, M. (2000), "Automating in the 21st Cen-tury Career and Technical Education", GreenhouseGrower, pp. 4-12.

7. Giacomelli G.A., and Ting K.C. (1995) "Transporta-tion and Robotics for Greenhouse Crop ProductionSystems", Acta Hort (ISHS), Vol 399, pp. 49-60.

8. Van Henten, E.J., Hemming J., Van Tuijl, B.A.J.,Kornet, J.G., Meuleman, J., Bontsema J. (2003), “Collision-free Motion Planning for a CucumberPicking Robot”, Biosystems Engineering, Vol 86, No. 2 pp. $135-144$

9. Pilarski, T., Happold, M., Pangels, H., Ollis, M.,Fitzpatrick, K., Stentz A. (2002), "The DementerSystem for Automated Harvesting", AutonomousRobots, Vol 13, pp. 9-20.

10. Gan-Mor S., Ronen B., Kazaz I., Josef S., BilankiY. (1997), "Guidance for Automatic Vehicle forGreenhouse Transportation", ACTA Horticulture, Vol 443, pp. 99-104.

\section{AUTHORS PROFILE}

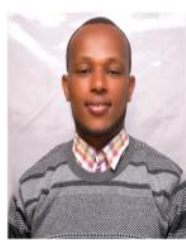

Ethiopia.

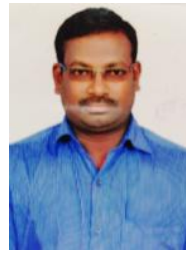

Mr. Ararso Taye Waktola, received his B.Sc. in Electrical and Computer Engineering (Electrical Power Engineering) from Debre Markos University, Ethiopia during July 6/2015Gc. He did his Masters of Technology (M.Tech) in Power System Engineering at Parul University, India during June 2018GC. Currently he works as the head of Electrical and Computer Engineering department at Bule Hora University,

J. SARAVANAN M.E., received his B.E in Electronics and Communication Engineering from Madurai Kamaraj University and Masters in Computer and Communication from Anna University. He has National and International teaching experience of more than 15 years. He published research papers based on Embedded Systems, IoT, Image Processing etc. His own area of interest includes IoT, Wireless Communication, Digital Communications. At present he works as a lecturer in Bule Hora University, Ethiopia.

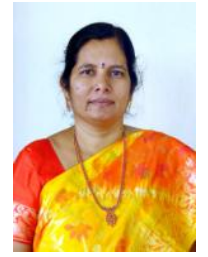

Dr B. Annapurna, Assoc. Prof. in Computer Science and Engineerig , Aditya College of Engineering , Surampalem , East Godavari Dt., AP, India. She has an excellent teaching experience of 24 years. She acquired her PhD from Acharaya Nagarjuna University on Data Mining Domain. She is convenor for a number of International Conferences. She organised many National seminars and Workshops. To her thrust of interest in Research she published 23 research papers on various domains in several International conferences and in Internationa Journals. 


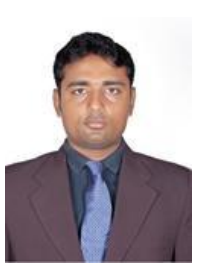

Raushan Kumar Singh is the M.Tech Gold Medalist from the department of Embedded System. He serves as the Technical Director of Spectrum Solutions, which is a Pondicherry, India based government approved academic event organising company. He chaired and organised several International Conferences / FDPs / Workshops / Project Expo / Guest Lectures and Robowars. He is the Editorial board member for several International Journals. He was Internationally Awarded by the First Vice President and the then Chief Justice of Supreme Court of Nepal for his excellence in Academic Events. His area of interest is immensely multidimensional. 